\title{
Bridging Instructional Gaps in Preparing to Teach Millennial Language Learners
}

\author{
Marjorie Hall Haley \\ George Mason University, Fairfax, Virginia, USA \\ Email: mhaley@gmu.edu \\ Reema A. Alsweel \\ George Mason University, Fairfax, Virginia, USA
}

\begin{abstract}
The United States Department of State issued a call for the need for "highly qualified" foreign/world language teachers in "critical need languages." Three languages that fall into this category are Arabic, Chinese, and Russian. In response to this call our teacher education program has actively sought ways to comply by providing multiple pathways and opportunities to fill the paucity of teachers in these three languages. This paper is the third study conducted at our university examining carefully structured learning sequences including face-to-face and online blended communities of practice that provide critical methodological training in transitioning teachers to learner-centered instruction for today's millennial learners. This study addressed the needs of 20 critical need language teacher participants in helping them bridge instructional gaps in preparing to teach millennial learners. Results indicated that teachers' notions about teaching were greatly influenced by their own cultural and experiential backgrounds.
\end{abstract}

Index Terms-teacher education, millennial learners, critical need language teachers, professional development, teacher identity

\section{INTRODUCTION}

The United States Department of State issued a call for the need for "highly qualified" foreign/world language teachers in "critical need languages." Three languages that fall into this category are Arabic, Chinese, and Russian. In response to this call our teacher education program has diligently sought ways to respond by providing multiple pathways and opportunities to fill the paucity of teachers in these three languages. There is an urgent need to expand the teaching force in these languages. The U.S. federal government recognizes the need to build our nation's language capacity as these are crucial to our economic growth (Committee for Economic Development, 2006) and national security (U.S. Department of Education, 2008).

Our university is a large public institution with more than 30,000 full time equivalent (FTE) students, located just outside Washington, DC. The Graduate School of Education is part of the College of Education and Human Development in which the Foreign/World Language Licensure program offers PK-12 teaching licenses in eight languages: Arabic, Chinese, Russian, Japanese, French, Spanish, German, and Latin. Thanks in large part to two generous grants, one from the Freeman Foundation and the other from StarTalk, we have been able to sponsor four summer institutes (SI) for Arabic, Chinese, and Russian teachers. The fourth summer institute, 2011, is the focus of the present study. It is a follow-up and continuation of research reported in "Understanding the perceptions of Arabic and Chinese teachers toward transitioning into U.S. schools," (xxxxx \& Ferro, 2011).

This three week institute, "Bridging Instructional Gaps in Preparing to Teach Millennial Learners," focused on learner-centered standards-based instructional practices and their advantages over traditional approaches. Further, examination was made of how varied approaches can be applied to language learning that will enhance teacher expertise, student performance, and lead to the creation of new materials for teaching Arabic, Chinese, and Russian.

The summer institute provided critical methodological training in transitioning teachers to learner-centered instruction for today's millennial learners. Twenty teacher participants in Arabic, Chinese, and Russian engaged in carefully structured learning sequences including face-to-face and online blended communities of practice. This included approximately 98 hours of instruction with graduate credit availability, that took place over a three week period.

Week one examined such themes as: planning and standards-based, learner-centered language instruction; teaching multi-level classes and staying in the target language; integrating differentiation of instruction through various games and interactive activities for diverse learners; exploring skills, strategies, and dispositions for addressing the needs of today's millennial learners, and alternative approaches to assessment. This week also included five days of professional development workshops designed to provide hands-on teacher training in the introduction and application of interactive approaches in teaching and learning that focused on today's millennial learners. Participants received professional development in the morning, with individual sessions for Arabic, Chinese and Russian. These interactions were 
followed by immediate engagement in the target language with a master teacher who also stressed topics such as the use of technology, curriculum development, assessment, culture and standards, learner-centered instruction and classroom management.

Day one featured the summer institute lead instructor who had three years of previous experience working with our summer institutes. She presented "Effective Planning for Millennial Learners Using Learner-Centered Instruction In a Standards-based Classroom." Day two was led by two content experts who presented, "Interactive Games for Millennial Learners." Day three highlighted the expertise of a noted world language educator in assessment, "Assessment: Providing Alternative Approaches for Today's Millennial Learners." This was followed on day four with a highly interactive workshop on "Teachers Acquiring Skills, Strategies, and Dispositions for Today's Millennial Learners." Day five was the culminating day of workshops that afforded teacher participants the opportunity to learn more about "Teaching Multiple Levels Simultaneously and Staying in the Target Language."

During week two teacher participants partnered with two area public school districts' StarTalk student programs and actively engaged in micro teaching simulations. These interactions offered immediate engagement in theory-to-practice focused on planning for millennial learners, curriculum development, assessment, culture and standards, learnercentered instruction and classroom management.

During week three of the institute teachers actively participated in a multimedia learning environment using the online platform, Ning. Ning is an online platform for people and organizations to create custom social networks. Ning offers educators the ability to create a community website with a customized appearance.

A significant component of the institute was the creation and maintenance of an actual learning community activity during which participants experienced the preparation, engagement, assessment, and reflection phases. The online segment of the summer institute provided rich insight into cultural and educational influences that shaped and informed these teachers' attitudes and dispositions about teaching and learning. During this week participants worked in whole group discussions online across the three languages or participated in discussions by language with the three respective master teachers.

The literature on preparing foreign/world language teachers to work in today's U.S. schools clearly documents the influences of identity, culture and experiential backgrounds. In the next section we highlight a brief review of this literature. We were also interested in covering information about today's millennial learners in order to further expand the context of the present study.

\section{LITERATURE REVIEW}

In "New dimensions in language teacher preparation: Bridging divides in critical need languages" (xxxxx et al, 2011) reported on two case studies that highlighted efforts to recruit and train teachers to enter U.S. schools as highly qualified Arabic and Chinese instructors. The two case studies illustrated efforts to address issues surrounding preparing teachers to transition into teaching in U.S. schools. These examinations helped illuminate the impact and importance of sound pedagogical training and on-going professional development opportunities.

According to Milner, Flowers, Moore, Moore, and Flowers, (2003) pre-service teachers often finish teacher education programs and enter the classroom without background knowledge regarding different cultures, religious practices, or different ethnicities. Many teachers foreign to the U.S. have never lived in or near a racially diverse neighborhood, not to mention attend or work in a school that is racially diverse. In light of this lack of exposure, preservice teachers rely on stereotypical misconceptions and myths to influence their work as teachers.

To prepare foreign/world language teachers to meet the needs of today's millennial learners, teacher education programs and professional development programs have shifted their foci. As Darling-Hammond and Richardson (2009) noted, "the most useful professional development emphasizes active teaching, assessment, observation, and reflection rather than abstract discussions" (p. 47). Wilbur (2007) found that though many foreign/world language teacher education programs have methods courses that focus on applying standards-based, learner-centered theory to practice, the transition for teachers is fraught with challenges. These challenges are further exacerbated for the majority of today's critical need language teachers.

This is because teachers, even those with limited prior pedagogical training, have already established a set of preconceived notions of what teaching and learning will look like in U.S. schools (Zhan, 2008). These preconceived notions about teaching and learning are embedded over time through experiential and cultural influences. They become part of teachers' identities and can be difficult to modify. Nonetheless, foreign/world language teachers, especially those formally educated outside the U.S., must learn how to relate to today's millennial learners if they hope to become successful and competent teachers.

Zhao (2009) noted the culture of American education values individual differences and that there exists an everincreasing attempt to protect one's individuality and creativity. This culture of education is in contrast to the cultures of education in many Arabic-speaking countries, China, and those countries that comprised the former Soviet Union. In those countries a higher value is placed on the collective than on the individual (Richardson, 2004; Zhao, 2009)

Foreign/world language teaching can no longer be looked at as mainly a linguistic task, but the attainment of communicative competence, thus teachers need to be equipped with the knowledge and skills to accomplish this. There is a relationship between teacher belief and teacher practice. Sercu (2006) conducted a study that focused on 
foreign/world language teachers' beliefs and cultural dimension of foreign/world language education. Two questions guided this research: (1) How can foreign language teachers' current professional self-concepts and language-andculture teaching practices be characterized, and how do these self concepts and teaching practices relate to the envisaged profile of the intercultural foreign language teacher? (2) Is it possible to speak of an "average culture-andlanguage teaching profile" that applies to teachers in a number of different countries?

The findings indicated that teacher knowledge should include familiarity with not only the language and its culture but also the language and culture of the students being taught. One of the most salient outcomes of this study was the focus on investigating teachers' beliefs about teaching intercultural competence in foreign/world language education and the necessity for providing teachers with professional development opportunities that build on their existing beliefs and teaching practices. The findings of research on teachers' beliefs indicate that teaching and learning affect their conceptions of specific teaching situations and ultimately their teaching practice (p. 69).

Bejaard et al (2004) completed a longitudinal study that examined teachers' professional identity. Identity was defined as not a "fixed attribute of a person, but a relational phenomenon" (p. 108). As with the present study, these researchers focused on teachers' concepts or images of self as they were strong determinants of developing as teachers and attitudes toward educational change.

\section{Millennial Learners}

Characteristics of millennial learners vary by region, depending on social and economic conditions. However, according to Wikipedia (2012) it is generally marked by an increased use and familiarity with communications, media, and digital technologies. Christy Price, EdD, a psychology professor at Dalton State College, became interested in millennial learners when she noticed a gap between students' expectations for success and the effort they put forth in the classroom (Price, 2010). This prompted a qualitative analysis of narratives provided by more than a hundred millennial learners to get a more accurate picture of how to meet the needs of these learners.

\section{Methodology}

This study, based on previous StarTalk research from 2009 and 2010, set out to examine and explore the perceptions of Arabic, Chinese and Russian teachers towards teaching in U.S. classrooms; focusing specifically on the different critical considerations that directly influence the transitioning of theses teachers to teaching in a learner-centered classroom with millennial learners. To examine the perceptions and transition of these teachers, the research questions were as follow:

1. What preconceived notions do Chinese, Arabic, and Russian teachers have about U.S. schools? For returning StarTalk Summer Institute (STSI) teachers, how have these notions changed or continue to be a challenge?

2. How do Chinese, Arabic, and Russian teachers define millennial Learners? How do they understand and address their needs?

3. What cultural backgrounds and teacher identities (understandings/expectations of teacher roles) do Arabic, Chinese and Russian teachers bring into U.S. schools?

4. In what ways has the online learning community helped to enhance professional development?

\section{A. Procedures}

After a careful analysis of our 2009 and 2010 research findings, the 2011 study was composed to extend the results and findings and to develop, grow and learn more about the perceptions, needs, and development of critical need language teachers. This led to the creation of instruments that would help this development; followed by the careful review of all the instruments; and finally obtaining the approval from the university's human subjects review board.

\section{B. Participants}

The participants for this study were all teachers attending the 2011 StarTalk summer institute (STSI) held in a large north-eastern university. Although participation in the study was completely voluntary, there were requirements for attending the STSI; these requirements included the number of StarTalk institutes attended, teaching status, and language(s) taught. Thus, the sample can be viewed as a purposeful, criterion based selection. Glesne (2006) explains careful selection, especially for qualitative studies, is done in order to select 'information-rich cases' that can lead to important issues to the research. The selection of participants for this study provided rich data to give the study depth (Creswell, 2005; Patton, 2002).

In the 2011 STSI there were a total of 20 Arabic, Chinese and Russian teachers (10 Arabic, 8 Chinese, and 2 Russian). For this study 11 of the 20 attendees participated in the qualitative portion of the research study, and 9 of those participated in the online surveys. The teacher participants were emailed a link to the consent form and the survey at the beginning of the summer institute.

All of the 2011 female teacher participants were either employed as Chinese, Arabic or Russian teachers at the time, or were interested in becoming a Chinese, Arabic or Russian teacher in the U.S. While some were U.S. born citizens, the majority were from a Chinese, Arabic or Russian speaking country.

Nine teachers participated in the online survey. Of those StarTalk survey teacher participants, five were employed as full time teachers in either public or private K-12 classrooms, with a few also teaching at college levels. Of the full time 
teachers, one held a foreign/world language license, and two were doing coursework to meet that goal; (one Arabic and one Chinese). Four teachers were pre-service at the time of the research and one held a foreign/world language license (Chinese) while one was working toward earning her license (Chinese). Additional information on teacher participants can be found in the table 1.1 below.

TABLE 1.1:

STSI 2011 TEACHER PARTICIPANT INFORMATION

\begin{tabular}{|l|l|l|l|}
\hline & Arabic $(\mathrm{n}=4)$ & Chinese $(\mathrm{n}=5)$ & Russian $(\mathrm{n}=2)$ \\
\hline Highest Degree Earned & & & $\mathrm{n} / \mathrm{a}$ \\
\hline Bachelor & 4 & 1 & $\mathrm{n} / \mathrm{a}$ \\
\hline Master & & 2 & $\mathrm{n} / \mathrm{a}$ \\
\hline Doctorate & & 2 & $\mathrm{n} / \mathrm{a}$ \\
\hline Employment/Licensure Status & & & \\
\hline In-service with license & 1 & & $\mathrm{n} / \mathrm{a}$ \\
\hline In-service no license & $3 *$ & $1 *$ & $\mathrm{n} / \mathrm{a}$ \\
\hline Pre-service with license & & 1 & $\mathrm{n} / \mathrm{a}$ \\
\hline Pre-service no license & & $3 *$ & $\mathrm{n} / \mathrm{a}$ \\
\hline$*$ Working on license & 1 & 2 & $\mathrm{n} / \mathrm{a}$ \\
\hline
\end{tabular}

During the second week of the summer institute the teacher participants split their time into two parts. One involved actively connecting theory to practice by presenting micro teaching demonstrations with StarTalk students in neighboring schools two days a week. These were followed by interviews conducted by the STSI lead researcher. The other time the teachers were involved with participating in an online discussion forum with the master language teachers from the STSI using Ning. During the third week, the teacher participants engaged in whole group discussions online during which they examined perceptions, expectations and concerns about working with millennial learners in U.S. schools. They also developed materials and actively became members of a community of practice. As mentioned earlier, 11 teachers participated in this portion of the study (4 Arabic, 5 Chinese, and 2 Russian).

\section{Instruments}

Pre and post-institute online surveys: These surveys were created using the online tool "Survey Monkey" that incorporated close-ended and open-ended reflection questions. Both the pre and post-institute surveys began with questions focused on collecting demographic data to account for any inconsistencies and fluctuation. This was followed by questions discussing teacher beliefs, learning theories, classroom roles, technology use, standards of foreign language learning, communicative modes, learner centered instruction, and general teacher concerns. The pre-institute survey ended with questions pertaining to what teacher participants hoped to gain from the institute and the online community; while the post-institute survey concluded with questions about their experiences and challenges in the StarTalk student programs and at the STSI. The pre and post-institute questions are provided in Appendix A.

Online discussion board Ning. During weeks two and three of the STSI, the teacher participants engaged in online discussions by responding to prompts posted by the master teachers and online facilitator. There were a total of 8 days of online whole group discussions with different prompts posted each day, as well as more focused prompts posted to each language group. Discussions during week two included perceptions and beliefs about teaching in U.S. schools, creating lesson plans in the target language, the sharing of ideas, and giving feedback on teaching materials posted by teacher participants. During week three, the discussions focused on learning and outcomes, motivation, target language use, assessment, cooperative learning, multiple intelligences, progress towards leaner-centered instruction, as well as identifying prominent classroom challenges and how to overcome them.

These online discussions were an extension of questions in our pre-institute survey and allowed the collection of more specific and detailed descriptions of the participants' beliefs, perceptions, preconceived notions, needs, challenges and outcomes. The full list of the online discussion prompts is provided in Appendix B.

Group and individual interviews. The interviews took place immediately after the teacher participants conducted their micro-teaching demonstrations in participating StarTalk schools. Most of the teachers participated in the group interviews. One requested an individual interview, and one chose to hand write her answers during a group interview as she did not wish to be audio recorded.

The questions included teacher participants' thoughts and reflections on information learned from their micro teaching experiences, how the lessons were planned and implemented, what worked or did not work during instruction and the reasons for that, and what they might do differently with future implementation of these standards-based, learner-centered activities. The interview questions are provided in Appendix C.

\section{Data Analysis}

Several rounds of data analysis were conducted. The first round began before data collection for the present study and consisted of carefully examining data from our previous STSI to understand the research directions and gaps that needed to be addressed. Once data were collected, open coding of the pre and post survey data, interviews and online discussions began. This meant, that although organizational codes (Maxwell, 2005) had been created prior to 
conducting the research, i.e. our research goals and interests, open coding allowed the substantive categories (Maxwell, 2005) to emerge, i.e. letting the data "speak for themselves" (Glesne, 2006, p.164).

This was followed by collapsing the data into broader categories and themes, thus connecting themes and finding relationships to create a whole (Patton 2002; Maxwell, 2005). Finally, constant-comparative data analysis took place (Creswell, 2005). This included the comparison of codes, categories and themes from all the data sources to eliminate redundancy and make further connections between themes. Throughout data analysis, research bias was addressed and accepted. By letting data speak for itself, and interacting with those themes, both researcher and participant voices came through. Addressing and accepting research bias also lead to what Maxwell (2005) describes as a search for more evidence to support findings.

\section{RESULTS AND DISCUSSION}

The purpose of this research was to build on previous StarTalk research from 2009 and 2010 and further gain a perspective on critical need language teachers' perceptions towards transitioning into U.S. schools. From our previous research and experiences we have concluded that teachers who have had a limited learning experience in a Western educational context can have a difficult time in transitioning to U.S. schools. These include, but are not limited to: moving towards learner-centered instruction; working with culturally, linguistically, and cognitively diverse learners; classroom management and discipline; assessment; teaching multi-level classrooms; staying in the target language; and meeting the needs of today's millennial learners, with the overall aim of becoming self aware, reflective teachers.

To understand this transition, we asked teacher participants to engage in daily reflection, participate in our surveys and share their thoughts and beliefs in the online discussion fora. The findings from these data sources shed light into this transition as well as the teachers' preconceived notions, their feelings regarding their roles and identities and the benefits of the STSI. What follow are the findings from the data that addressed our research questions.

1. Research question 1: What preconceived notions do Arabic, Chinese, and Russian teachers have about U.S. schools?

The teacher participants were surprised and happy to find that the students were motivated, well behaved, and openminded. "They were not crawling on the floor. I really had a different impression." "They are willing to work. They want to work." (Chinese, teacher interview) "I think they are easy to interact with, umm you know very friendly, and they are smiling... and they are quiet a lot and I really had a different impression, you know, but they actually wanted to learn, I was really surprised." (Arabic teacher interview).

For returning STSI teachers, how have these notions changed or continue to be challenged?

The data show that the StarTalk summer institute had a positive impact on the teacher participants' knowledge and understanding of millennial learners and how to address their needs using technology, student-centered activities, and one discussed her need to catch up to them. The pre-survey showed that only $25 \%$ of participants stated that they had heard of millennial learners and were familiar with their needs and how to address them. The findings also show that $100 \%$ of participants felt they knew about learner-centered instructional practices well enough to apply them to their teachings in the post survey compared to $37.5 \%$ in the pre-survey. The post survey data also showed that $100 \%$ of the teacher participants felt familiar enough with the Standards for Foreign Language Learning and the Communicative Modes to apply them to their teaching as compared to $62.5 \%$ in the pre- survey.

In the interviews the teacher participants discussed the theories and techniques they applied from the STSI to their micro-teaching demonstrations, as well as discuss others that had an impact on them and they plan to use in the future.

"You know I went to the first summer institute. From that I learned a lot and applied to my teaching, and this time I felt it's different a lot... even in the lunch break when we chat we communicate and we exchange ideas. I learned a lot. You know we can talk about staying in the target language with the guest speakers since they are different and have different points of view." (Chinese teacher interview)

"This is a life experience for me. What I learned last week I am doing it this week with real students." (Arabic teacher interview)

When discussing their concerns, the teacher participants made a significant shift in the post-survey results after the summer institute as compared to the pre-survey. This included a positive attitude towards using and staying in the target language in the classroom; getting students motivated and interested in the class; dealing with behavioral problems; using technology and talking with parents. However, the results also showed that a great number (44.4\%) still felt that assessment, both in creating an integrated performance-based assessment (IPA) and evaluating a performance based assessment, was of a moderate to a great concern.

The open ended questions in the survey focused on teacher roles, challenges during instruction and how to overcome them, millennial learners and the benefits of an online community (Ning), and concluded with what they would like to see in future StarTalk institutes.

\section{Research Question 2: How do Arabic, Chinese, and Russian teachers define millennial learners? How do they understand and address their needs?}

The survey data show that the StarTalk institute had a positive impact on the teacher participants' knowledge and understanding of millennial learners and how to address their needs using technology, student-centered activities. The 
pre-survey showed that only $25 \%$ of the participants knew something about millennial learners or were familiar with their needs and how to address them.

During the online forum, the teacher participants discussed their views and knowledge about millennial learners, explaining that they were facing a whole new generation of students who require a different way of learning and teaching. As one Chinese teacher discussed, "the biggest change of my view about millennial language learners is that they negotiate their learning and appropriate what they learn to their own purpose. In other words, it is not the teacher who decides what, when and how students learn."

Teacher participants also discussed the importance of technology in reaching and understanding the millennial learners. It is a new concept to many, as indicated in the survey, as one Chinese teacher discussed

The very concept of millennial learners itself has been truly illuminating to me in that I now understand the substantial differences in learning styles and instructional needs between the digital natives and digital immigrants. To meet their needs, I need to consciously come out of my comfort zone, to put myself into a constant mode of searching for ways to meet the millennial learners' needs.

"The very concept of millennial learners itself has been truly illuminating to me in that I now understand the substantial differences in learning styles and instructional needs between the digital natives and digital immigrants. To meet their needs, I need to consciously come out of my comfort zone, to put myself into a constant mode of searching for ways to meet the millennial learners' needs." (Chinese teacher on Ning)

"They can accept new stuff very quickly. They grow really fast both physically and psychologically." (Chinese teacher on Ning)

"I have come to understand that the millennial learners are a whole new generation and require very different ways of teaching." (Chinese teacher's view about Ning)

3. Research Question 3: What cultural backgrounds and teacher identities (understandings/expectations of teacher roles) do Arabic, Chinese, and Russian teachers bring into the U.S. schools?

The teacher participants discussed the different cultural backgrounds they bring into the classroom. Of particular interest was that the question of cultural background was never addressed directly, but many teachers compared their own education and background and the differences with that of U.S. education.

Collaboration was also a concern for other teachers, "You have to be very flexible and you have to be um it's a group lesson it's a team play. It's a team work so you have to be very flexible thinking about the focus. The focus is the lesson and so everybody will be contributing to that focus and then as a teacher you have to learn how to collaborate because it takes a lot of collaboration ...We are language teachers. We are trying to incorporate as much as possible but at some point you have to collaborate with other people so you have to learn. So the coordination is the most important thing, the most challenging thing and the most satisfying thing for the results, if you do well (laughs)." (Chinese teacher interview)

Both Chinese and Arabic teachers admitted that their educational backgrounds revolved around rote memorization and teacher-centered instruction. "The same as they teach us back home, ok teachers say 'listen and repeat,' 'listen and repeat." (Arabic and Chinese teachers' interview). One Chinese teacher was surprised and noted, "You have to be flexible with them, compared to in China, like when we were in the classroom you know teacher told us something we just follow, so whatever teacher tell us we just follow you don't ask questions you don't you know, but with American students they will ask questions."

"The biggest change of my view about millennial language learners is they negotiate their learning and appropriate what they learn to their own purpose. In other words, it is not the teacher who decided on what, when and how to learn." (Chinese teacher on Ning)

"'Learning is fun' is much embraced, while Chinese teachers and students would rather endorse the notion that 'learning is not fun' but a painful process which can exemplified in many Chinese household sayings, such as 'the sea of learning is boundless and only ship of adversities and diligence can tide you over'. (Xuehai wuya ku zuo zhou)(Chinese teacher on Ning)

"Most of the students I ever worked with in China are hard-working, and it seems that few teachers cared how to arouse their motivation and curiosity. In U.S., I found that it is teachers' responsibility to engage students, and to inspire students' desire to learn." (Chinese teacher on Ning)

\section{Teacher's roles in the classroom:}

When discussing the teacher's role in the post-survey, most teacher participants focused on the importance of being a facilitator and organizer of the classroom while keeping the students at the center of teaching and learning.

\section{Question 4: In what ways has the online learning community helped to enhance professional development?}

While discussing the online learning community the teacher participants were excited in the pre-survey to connect and learn from others as well as share lesson plans and resources. After using Ning during the summer institute the participants felt that the online community was very helpful in the sharing of ideas and resources, getting feedback from peers, as well as building strong relationships with other teachers. However, many felt that it could sometimes be overwhelming. 
While discussing how Ning impacted their teaching, many believed that it could help them achieve their goal of student-centered instruction, using technology in the classroom and having an online form platform where students can stay connected.

In their online discussions teachers shared resources as well as continuously gave feedback to each other on materials and lesson plans posted (both in the target language and English). The following diagram (Figure 1) illustrates the usefulness of the online learning community:

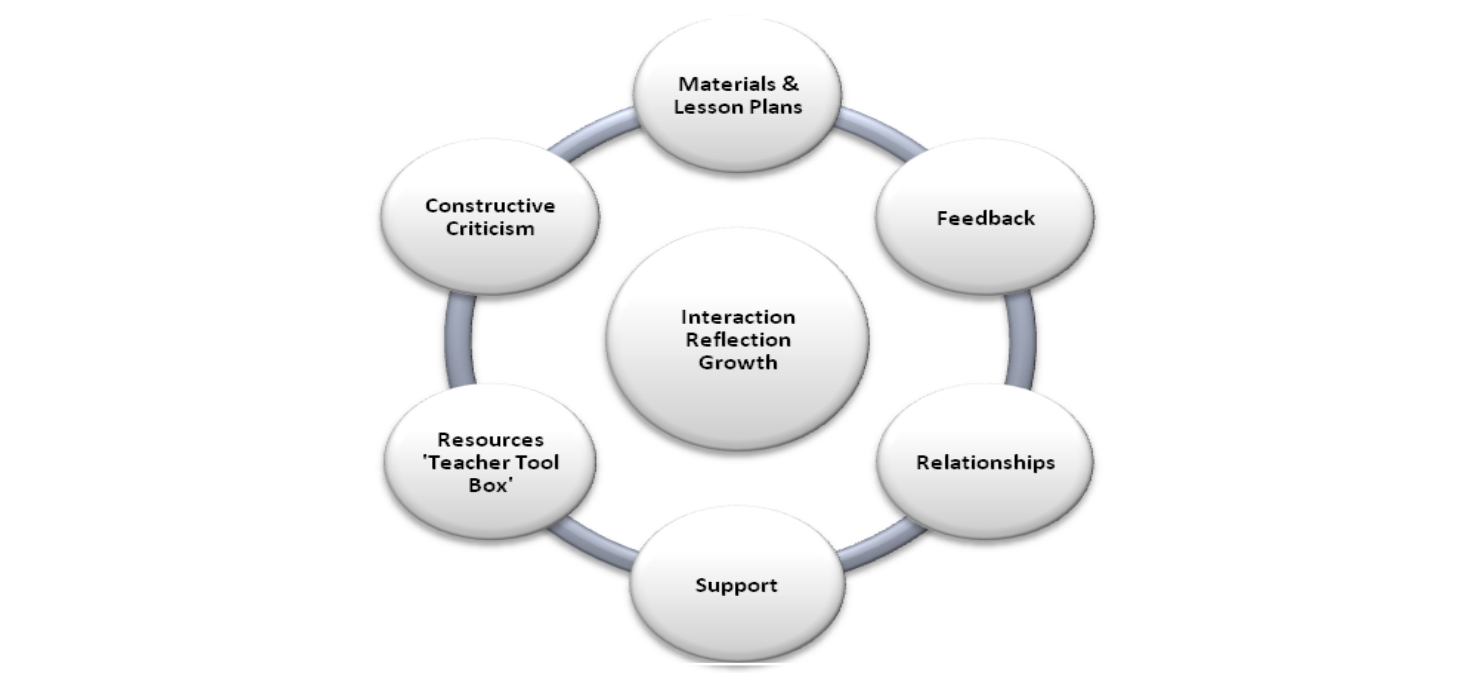

Figure 1: An online community building experience

\section{Future workshops}

Teacher participants were asked what they would like to see in future StarTalk workshops. The following are their responses:

\begin{tabular}{|l|l|}
\hline 1 & Classroom management methods \\
\hline 2 & $\begin{array}{l}\text { I want to see more intercultural elements in the teacher' development. Since students will become global citizens by learning a foreign } \\
\text { language, how do we make sure that teachers have broad visions in cultivating students' intercultural awareness? }\end{array}$ \\
\hline 3 & Technology, group work, feedback, summative assessments, rubrics in the target language \\
\hline 4 & $\begin{array}{l}\text { I would like to observe and study an entire teaching process of a master teacher in my TL area: from lesson planning/lesson plans to } \\
\text { teaching/instruction/classroom management to assessment. While observing the entire process, I would like to have opportunities to talk } \\
\text { to the master teachers to understand how and why and what he/she thinks/does... }\end{array}$ \\
\hline 5 & Managing different levels in the classroom, more RUBRICS???? \\
\hline
\end{tabular}

\section{CONCLUSION}

Arabic, Chinese, and Russian are three of 13 languages that have been designated as "critical need languages" by the U.S. Department of State. There is an urgent need to expand the teaching force in these languages. However, teaching Arabic, Chinese, and Russian in U.S. schools is challenging for teachers who were trained outside the U.S. and may not be familiar with millennial learners. The present study examined bridging instructional gaps in preparing to teach millennial language learners. We discovered that similar to our earlier findings (xxxx, Ferro, 2011) Arabic, Chinese, and Russian teacher participants hold two very different views on foreign/world language teaching and learning: First, their own language learning experiences greatly influence their current perceptions. For the majority of them, these experiences were in teacher-centered classrooms in which the goal was mastery of grammar and vocabulary, relying heavily on rote memorization. Second, these teachers readily acknowledged the importance of understanding the needs of today's millennial learners. Further, they were open and receptive to not only gaining insight into accommodating today's language learners, but sought meaningful ways to conceptualize ways to plan lessons and provide assessments that strengthened their teaching.

There are two additional noteworthy findings that emerged from this study: (1) There were teacher participants who came to the STSI with negative pre-conceived notions about teaching U.S. students. Their views were quickly changed during the workshop activities, working in the target language with a master teacher, actively engaging in the online learning community, and ultimately conducting micro teaching demonstrations with StarTalk student programs. (2) Introducing our teacher participants to an online learning community was challenging in that many were not familiar with this level of technology use. However, the added benefit was that teachers were able to communicate in either English or their target languages (TL). They were further supported by the three respective master teachers and these discussions were available for just one TL group or shared across all three language groups. Since many critical need language teachers can sometimes feel isolated in their schools or school districts, the online community provided a way for teachers to share ideas, resources, and build strong communities of practice. 
We will continue our research in an effort to learn more about the needs of critical need language teachers and how we can best provide training in helping them to navigate the transition into teaching in U.S. schools. The research we report on in this paper grew out of our commitment to excel in providing leading, cutting edge preparation and training for critical need language teachers. Our teacher licensure program model can best be described as "additive" because we highly value the skills and dispositions our teacher participants bring. While our efforts are intended to help these individuals navigate the cross-cultural obstacles they sometimes encounter in preparing to teach in the U.S., we work tirelessly to ensure that their cultural and linguistic identities and backgrounds are not diminished.

\section{End Notes}

\section{StarTalk}

STARTALK is the newest of the component programs of the National Security Language Initiative (NSLI) announced by former President Bush in January of 2006. The initiative seeks to expand and improve the teaching and learning of strategically important world languages that are not now widely taught in the US. Other programs under the NSLI umbrella include Title VI/Fulbright Hays programs of the US Department of Education, The National Security Education program of the National Defense University, and study abroad and exchange programs of the US Department of State.

STARTALK's mission is to increase the number of Americans learning, speaking, and teaching critical need foreign languages by offering students $(\mathrm{K}-16)$ and teachers of these languages creative and engaging summer experiences that strive to exemplify best practices in language education and in language teacher development, forming an extensive community of practice that seeks continuous improvement in such criteria as outcomes-driven program design, standards-based curriculum planning, learner-centered approaches, excellence in selection and development of materials, and meaningful assessment of outcomes.

\section{The Freeman Foundation}

The Freeman Foundation was established in 1994 through the bequest and in memory of the businessman and benefactor Mansfield Freeman, a co-founder of the international insurance and financial conglomerate American International Group, Inc., better known as AIG. This private and philanthropic foundation, based in Stowe, Vermont, with offices in New York City, is dedicated to augmenting international understanding between the United States and the nations of East Asia.

\section{APPENDIX A PRE AND POST-INSTITUTE SURVEY}

1. What is your home country?

2. What is your gender?

3. What is the highest degree that you have earned?

4. Do you have teaching experience? - yes - no

- what subject(s) did you teach?

- what grade(s)?

- where (country)?

- for how long?

5. Do you currently hold a foreign/ world language teaching license or certificate in the United States?

- If you do not hold a teaching license in the U.S., are you currently working on the licensure requirements?

6. Are you employed as a language teacher in a U.S. school? - yes - no

- public school

-private school

7. What language(s) do you teach or will you teach?

- Chinese

-Arabic

- Russian

8. [Post-Institute survey: Now that you have attended the STSI] Check the statement that best describes your familiarity with 'millennial learners'?

- I have heard of millennial learners and am familiar with their needs and how to address them

- I have heard of millennial learners but I am not sure how to address their needs

- I have never heard of the term millennial learners

9. [Post-Institute survey: Now that you have attended the STSI] Check the statement that best describes your knowledge and understanding of learner-centered instructional practices:

- I know about learner-centered instructional practices well enough to apply them to my teaching

- I know about learner-centered instructional practices, but I am not sure how to apply them in my teaching

- I have heard of learner-centered instructional practices, but I do not know much about them

- I have never heard of learner-centered instructional practices 
10. [Post-Institute survey: Now that you have attended the STSI] Check the statement that best describes your knowledge and understanding of the Standards of Foreign Language Learning (The 5Cs):

- I know the standards well enough to apply them to my teaching

- I know the standards, but I am not sure how to apply them in my teaching

- I have heard of the standards, but I do not know much about them

- I have never heard of the standards

11. [Post-Institute survey: Now that you have attended the STSI] Check the statement that best describes your knowledge and understanding of the 3 Communicative Modes (interpretive, interpersonal, presentational):

- I know the 3 Communicative Modes well enough to apply them to my teaching

- I know the 3 Communicative Modes, but I am not sure how to apply them in my teaching

- I have heard of the 3 Communicative Modes, but I do not know much about them

- I have never heard of the 3 Communicative Modes

12. [Post-Institute survey: Now that you have attended the STSI]Please rate the following concerns about teaching U.S. students:

\begin{tabular}{|l|l|l|l|l|}
\hline Not a concern for me & An occasional concern for me & A moderate concern for me & A great concern for me & \\
\hline
\end{tabular}

- Using the target language during my instruction

- Motivating students to use the target language

- Getting students to care about my class

- Creating interesting activities for my students

- Talking to a student who is not behaving in class

- Using technology in my lessons

- Getting students to participate in small group activities

- Creating an integrated performance-based assessment

- Evaluating a performance-based assessment

- Talking to a parent/guardian about a student's grade

\section{PRE-INSTITUTE:}

13. What do you hope to learn/gain from this StarTalk workshop?

14. What do hope to gain from an online community?

15. From your experience, what are some ways teachers can help students learn a language?

16. What do you believe a teacher's role is in the classroom?

17. What technology applications are you currently using in the classroom?

\section{POST-INSTITUTE:}

13. Please describe the learner-centered activities you were able to use with the students in the language camps.

14. Were your learner-centered activities connected to the standards? If so, how?

15. What were some of the challenges you faced while implementing learner-centered activities?

16. What did you do to overcome these challenges?

17. After teaching in the language camps, did your opinion change regarding

teacher role in the classroom? If yes, explain.

meeting the needs of millennial learners? If yes, please explain

18. What do you believe you need to do to further your professional development as a language teacher?

19. During Week 3 of the summer institute, you participated in many online discussions. What was the most helpful discussion during the online portion of the workshop? Why was this discussion so helpful to you?

20. What did you learn from the online community?

21. How will your experience on Ning impact your teaching?

22. What did you like and dislike about Ning?

23. What topics or themes would you like to see included in future workshops?

\section{Appendix B The Week 2 And 3 OnLine Discussion Questions Ning LeARning Community}

\section{Week 2: Two days working with master teachers}

Day 1: Reflection on Week 1 Discussion Prompts (NOTE: MTs may use a graphic organizer to facilitate these online discussions.)

i. Name at least 3 significant ideas that you learned during the interactive workshops last week.

ii. How will these ideas help you meet the needs of millennial language learners?

iii. What concepts or ideas from Week 1 workshops are unclear?

iv. How will you use what you learned during the workshops in your teaching?

Day 2: Create one standards-based activity using any of the topic(s) presented during the Workshops. You may produce it in the target language and post it as an attachment to your response. In your response:

i. Describe your standards-based activity and how it is age, grade level, and language-level appropriate. 
ii. Explain how it will meet the needs of a millennial language learner.

iii.Review and comment on two other activities from your group.

Please use the following format:

- Which of the 5Cs apply to this activity?

- Which of the 3 modes apply to this activity?

- Here are some suggestions for improving this activity: ...

Week 3: Five days working with Online Facilitator

Day 1: Millennial Learners, Beliefs and Using the Target Language

Whole Group Questions:

During week 1, you experienced 5 days of professional development to help you better meet the needs of millennial language learners. Some of you have been working with millennial learners for several years and some of you have just had your first experience teaching millennial learners.

- What were your previous views of millennial language learners?

- How have your views of millennial language learners changed?

Some of you have been working with U.S. students for several years and some of you have had your first experience with teaching U.S. students in the last two weeks.

- What views/feelings did you have about teaching U.S. students before you ever worked with them? How have your views changed?

Small Group Questions: Target Language

- What worked well in your use of the TL during your lessons last week? What areas can you identify for improvement?

- Watch video. How did the teacher use the target language to provide comprehensible input for the students? What would you do differently?

- What elements from the video can you incorporate into the lesson you used last week?

Post a revised lesson and provide peer feedback to at least one other group using the checklist provided:

- Which of the 5Cs apply to this activity?

- Which of the 3 modes apply to this activity?

- Here are some suggestions for improving this activity: ...

\section{Day 2: Motivation and Millennial Learners}

Whole Group Questions:

Why did you study a foreign language? What were your motivations?

What motivates students to learn a foreign language? How does their motivation influence your teaching style?

Small Group Questions: Motivation during Lesson

- What worked well in your first lesson last week? What areas can you identify for improvement?

- Watch video. What worked well in the video? What would you do differently?

- What elements from the video can you incorporate into the lesson you used last week?

Post a revised lesson and provide peer feedback to at least one other group using the checklist provided.

Day 3: Classroom Management and Millennial Learners

Whole Group Questions:

In your experience, what aspects of classroom management (discipline, organization, record keeping, managing groups, teaching in the target language) are/will be challenging for you? What challenges would you like to address in the upcoming year?

\section{Small Group Questions: Classroom management}

- What worked well in your first lesson last week? What areas can you identify for improvement?

- Watch video. What worked well in the video? What would you do differently?

- What elements from the video can you incorporate into the lesson you used last week?

Post a revised lesson and provide peer feedback to at least one other group using the checklist provided.

Day 4: Assessment and Millennial Learners

\section{Whole Group Questions:}

What are your challenges in using performance-based assessment? What areas or challenges would you like to learn more about as you move forward?

\section{Small Group Questions: Assessment}

- What worked well in your first lesson last week? What areas can you identify for improvement?

- Watch video. What worked well in the video? What would you do differently?

- What elements from the video can you incorporate into the lesson you used last week?

Post a revised lesson and provide peer feedback to at least one other group using the checklist provided.

Day 5: Cooperative Learning and Millennial Learners

Whole Group Questions: 
What aspects of cooperative learning are challenging for you? How are they different from your educational experience? How do you view the role of the teacher in setting up cooperative learning activities?

What would you like to learn more about as you move forward in your career?

\section{Small Group Questions: Cooperative Learning}

-What worked well in your first lesson last week? What areas can you identify for improvement?

- Watch video. What worked well in the video? What would you do differently?

- What elements from the video can you incorporate into the lesson you used last week?

Post a revised lesson and provide peer feedback to at least one other group using the checklist provided.

\section{APPENDIX C POST-TEACHING GROUP INTER VIEW PROTOCOL}

\section{Questions:}

1. Let's begin by introducing ourselves. Please tell us your name.

2. Could you share with us how you planned and designed your activities for your lesson today? For example:

a. Why did you choose your topic or theme?

b. What learner-centered activities did you have planned?

c. Can you tell us how your activities connect to the standards?

d. Do you think you were able to "connect" with millennial learns? How?

3. What worked well during your instruction? Why do you think/ feel it worked well?

4. What did not work so well during your instruction? Why do you think/ feel it didn't work so well?

5 . What would you do differently the next time you try these kinds of activities?

6. How could you tell if the students were understanding and learning?

7. What did you learn about yourself as a teacher?

8. What did you learn about U.S. students?

9. Is there anything else you would like to say about teaching the students in the language camps?

Closing: Thank the individuals for their cooperation and participation in the group interview. Assure them that their names/identities will be kept confidential.

\section{REFERENCES}

[1] Bejaard, D., P. C. Meijer. \& Verloop, N. (2004). Reconsidering research on teachers' professional identity. Teaching and Teacher Education 20.2, 107-128. doi:10.1016/j.tate.2003.07.001

[2] Committee for Economic Development. (2006). Education for global leadership: The importance of international studies and foreign language education for U.S. economic and national security. http://www.ced.org (accessed 3/1/2012).

[3] Creswell, J. W (2005). Educational research, (2 $2^{\text {nd }}$ edn.). Upper Saddle River, New Jersey: Pearson Education.

[4] Darling-Hammond, L. \& N. Richardson (2009). Teacher learning: What matters? Educational Leadership, 66.5, 46-53.

[5] Glesne, C (2006). Becoming qualitative researchers: An introduction ( ${ }^{\text {rd }}$ edn.). New York: Allyn \& Bacon/Longman.

[6] Xxxxx, \& M. Ferro. (2011). Understanding the perceptions of Arabic and Chinese teachers toward transitioning into U.S. Schools. Foreign Language Annals, 44.2, 289-307. doi:10.1111/j.1944-9720.2011.01136.x

[7] Xxxxx, R. Grant, M. Ferro \& S. Steeley. (2011). New dimensions in language teacher preparation: Bridging divides in critical need languages. US-China Foreign Language 9.1, 45-54.

[8] Maxwell, J (2005). Qualitative research design: An interactive approach (2 ${ }^{\text {nd }}$ edn.). Thousand Oaks, CA: Sage.

[9] Milner, H. R., L. A. Flowers, E. Moore, J. L. Moore \& T. Flowers. (2003). Preservice teachers' awareness of multiculturalism and diversity. The High School Journal, 87.1, 63-70. doi:10.1353/hsj.2003.0018

[10] Patton, M. Q (2002). Qualitative research and evaluation methods ( $3^{\text {rd }}$ edn.). Thousand Oaks, CA: Sage Publication, Inc.

[11] Price, C (2009). Why Don't My Students Think I'm Groovy? The Teaching Professor, 23.7, 7-8.

[12] Richardson, P.M (2004). Possible influences of Arabic-Islamic culture on the reflective practices proposed for an education degree at the Higher Colleges of Technology in the United Arab Emirate. International Journal of Educational Development, 4 , 429-436. doi:10.1016/j.ijedudev.2004.02.003

[13] Sercu, L. (2006). The foreign language and intercultural competence teacher: The Acquisition of a new professional identity. Intercultural Education, 17, 55-72. doi:10.1080/14675980500502321

[14] U.S. Department of Education. (2008). Enhancing foreign language proficiency in the United States: Preliminary results of the National Security Language Initiative. Office of Post-secondary Education. http://www.ed.gov/about/inits/ed/competetiveness/nsli (accessed 3/1/2012)

[15] Wikipedia (2012). http://en.wikipedia.org/wiki/Generation_Y (accessed 2/1/2012)

[16] Wilbur, M.L (2007). How foreign language teachers get taught: Methods of teaching the methods course. Foreign Language Annals, 40, 79-101. doi:10.1111/j.1944-9720.2007.tb02855.x

[17] Zhan, S (2008). Changes to a Chinese pre-service language teacher education program: Analysis, results, and implications. Asia-Pacific Journal of Teacher Education, 36, 53-70. doi:10.1080/13598660701793392

[18] Zhao, Y (2009). Catching up or leading the way: American education in the age of globalization. Alexandria, VA: Association for Supervision and Curriculum Development. 


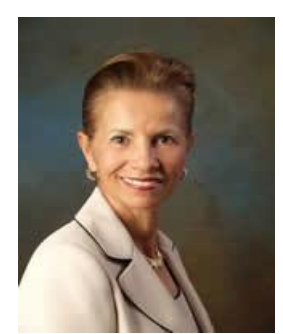

Marjorie Hall Haley is tenured Professor of Education and Director of Foreign Language Teacher Licensure in the Graduate School of Education at George Mason University in Fairfax, VA. She is a former Spanish, French, German, and ESL teacher of 14 years. Dr. Haley holds a PhD in Foreign Language Education and English as a Second Language (1986) from the University of Maryland, College Park (USA). She has also earned a Master's degree in education and advanced studies certificates from Towson University and Johns Hopkins University (USA), respectively.

In her 24th year at George Mason University, she teaches Foreign Language methods and ESL methods courses as well as doctoral courses in Brain-compatible Teaching and Learning, Bilingualism and Second Language Acquisition Research. She is actively involved in ongoing action research projects with teachers at local, national, and international levels. She has conducted four international teacher action research studies focused on the impact of implementing the Multiple Intelligences theory in foreign/second language classes. These studies included over 3,000 students in 14 states and 6 countries. In 2002 George Mason University awarded her its Outstanding Faculty Award in Teaching.

Dr. Haley's research and publication record is wide. Her most recent book is, Brain-compatible Differentiated Instruction for English Language Learners (2010). In addition, she is a featured scholar in the WGBH and Annenberg/CPB video, "Valuing Diverse Learners" available at www.learner.org Dr. Haley's earlier book, Content-Based Second Language Teaching and Learning: An Interactive Approach (2004), continues to be widely used and was recently translated into Mandarin.

Reema A. Alsweel is a PhD candidate in Multilingual Multicultural Education at George Mason University in Fairfax, Virginia. She also holds an MA in TESOL (2006) from San Jose State University in San Jose, California. She has taught ESL/ EFL at graduate and undergraduate levels in both the United States and Saudi Arabia. Most recently she has been involved with English language programs at George Mason University.

Her research interests include issues of cultural/ social roles and multiple identities and the impact of a second language, focusing specifically on the impact of English on Saudi women's roles and identities. She has conducted studies whose results were presented at conferences and symposiums nationally and internationally. 